(c) American Dairy Science Association, 2003.

\title{
Leptin Concentrations in Relation to Energy Balance, Milk Yield, Intake, Live Weight, and Estrus in Dairy Cows
}

\author{
S. C. Liefers, ${ }^{\star} \dagger$ R. F. Veerkamp, ${ }^{*}$ M. F. W. te Pas, ${ }^{\star}$ C. Delavaud,‡ \\ Y. Chilliard, $\neq$ and $T$. van der Lende $†$ \\ *Division of Animal Sciences, Institute for Animal Science and Health, \\ ID-Lelystad, PO Box 65, 8200 AB Lelystad, The Netherlands \\ †Animal Breeding and Genetics Group, \\ Wageningen Institute of Animal Sciences, \\ Wageningen University, Wageningen, The Netherlands \\ $\ddagger$ Herbivores Research Group, INRA-Theix, \\ 63122 St-Genes-Champanelle, France
}

\begin{abstract}
The objective of this study was to describe fluctuations in leptin concentrations during late pregnancy and lactation and to investigate how those fluctuations are related to energy balance, milk yield, milk components, dry matter intake, live weight, first postpartum luteal activity, and first observed estrus during lactation. Live weight, dry matter intake, energy balance, and milk yield were measured weekly on 304 primiparous Holstein cows for the first $80 \mathrm{~d}$ of lactation. The first postpartum luteal activity was determined by measuring milk progesterone, and independently, first observed estrus. For measuring leptin concentrations from $30 \mathrm{~d}$ before until $80 \mathrm{~d}$ after calving, blood samples were taken at 2 -wk intervals at a fixed time of the day after milking but before feeding. Leptin concentrations were high during pregnancy and declined to a nadir at parturition. It seems that leptin concentrations reflect the state of energy balance during lactation; plasma leptin concentrations were lower in cows with a mean negative energy balance during lactation. Those cows usually produced more milk, consumed less feed, and had a lower live weight compared with cows having a mean positive energy balance. The recovery of leptin concentrations from the leptin nadir at parturition seemed to depend on the extent and duration of the negative energy balance, thus probably on the amount of fat that was re-accumulated. Although there was lack of a relationship between leptin and first postpartum luteal activity, higher leptin concentrations associated with shorter intervals to first observed estrus might indicate a relationship between leptin and expression of estrus.
\end{abstract}

Received June 26, 2002.

Accepted October 2, 2002.

Corresponding author: S. C. Liefers; e-mail: s.c.liefers@id. wag-ur.nl.
(Key words: leptin concentrations, lactation, energy balance, reproduction)

Abbreviation key: EB = energy balance, $\mathbf{F E}=$ first observed estrus, FPLA = first postpartum luteal activity, LEPpost = mean concentration of leptin during the postpartum period, LEPpre = mean concentration of leptin during the prepartum period, $\mathbf{L W}=$ live weight, $\mathbf{M Y}=$ milk yield .

\section{INTRODUCTION}

Leptin, mainly produced in adipose tissue, inhibits feed intake (Morrison et al., 2001) and down-regulates adipose tissue deposition (Halaas et al., 1995). Block et al. (2001) showed that leptin is negatively correlated with the amount of nonesterified fatty acids, which reflects the amount of fat mobilization. Furthermore, there is evidence that leptin positively influences fertility. For example, leptin was reported to restore fertility in leptin deficient $o b / o b$ mice (Chehab et al., 1996) and to accelerate the onset of puberty in normal female rodents (Ahima et al., 1997). Also, fluctuations in plasma leptin concentrations appear to be related to LH concentrations in sheep (Nagatani et al., 2000).

As leptin affects both fat deposition and LH concentrations, it could play an important role in the processes occurring during the lactation period in dairy cows. During early lactation, cows are in a state of negative energy balance (EB) and fat stores are first used for lactation, maintenance, and growth with reproductive processes receiving the lowest priority (Mwaanga and Janowski, 2000). The negative EB suppresses the LH pulse frequency, resulting in a delayed first ovulation (Jolly et al., 1995). Canfield and Butler (1990) showed that the interval from parturition to the nadir in EB is positively correlated with the interval from parturition to first ovulation. Veerkamp et al. (2000) found a genetic correlation between start of luteal activity and energy balance of -0.60 . 
Although leptin concentrations during lactation have been described in dairy cows (Kadokawa et al., 2000; Block et al., 2001), to our knowledge, no study linking leptin with production and reproduction traits has been reported. Therefore the objective of this study was to describe fluctuations in leptin concentrations during late pregnancy and lactation and relate these to differences in energy balance, milk yield, milk components, DMI, live weight, first postpartum luteal activity, and first observed estrus during lactation.

\section{MATERIALS AND METHODS}

\section{Animals and Traits}

Between 1990 and 1997, 304 Holstein-Friesian primiparous cows were followed from 4 wk before until 15 wk after calving. Of those 304 cows, 230 cows participated in the breeding program of CR-Delta (Arnhem, The Netherlands) and 74 cows originated from the IDLelystad farm ('t Gen). During the first 15 wk of lactation DMI, milk yield (MY), and live weight (LW) were measured. Milk samples were taken at a fixed day of the week for measurement of fat, protein, and lactose yields. Cows were housed inside with controlled lighting in addition to daylight (total $17 \mathrm{~h} / \mathrm{d}$ light). Temperature was not regulated. Cows were fed ad libitum with a complete ration of artificially dried grass (mixed pasture containing mainly rye grasses), corn silage and concentrates, and food intakes were recorded daily using automated food intake units. Energy balance (MJ/d) was calculated as the difference between energy intake and calculated energy requirements for milk, fat, and protein yields and maintenance costs as a function of live weight. Milk progesterone was measured twice a week for the first $100 \mathrm{~d}$ of lactation to determine the interval between calving and first postpartum luteal activity (FPLA), and independently, first estrus (FE) was recorded by farm staff until $250 \mathrm{~d}$ after parturition. For more details on this material, see Veerkamp et al. (2000).

\section{Leptin RIA}

From $30 \mathrm{~d}$ before up to $80 \mathrm{~d}$ after calving, blood samples were taken at 2 -wk intervals at a fixed time of the day after milking but before feeding. Leptin concentrations were determined by RIA essentially as described by Delavaud et al. (2000) but with three slight modifications: (1) antibody 8172 was used instead of antibody 7137 because this antibody showed higher titers, (2) a final dilution of 1:45,000 was used instead of 1:15,000, and (3) bound and free ligands were separated using anti-rabbit-SACCEL (IDS Ltd. England) instead of anti-rabbit ram plasma. The coefficients of variation were $11 \%$ within assay and $8.5 \%$ between assays.

\section{Analyses}

Lactation curve for leptin. Initially, leptin concentrations were described by fitting a smoothing spline function in ASREML (Gilmour et al., 2001) for DIM using all 2066 measurements on 304 primiparous cows. Fixed effects were sample date, except when the effect of months of measurement was estimated, genetic group (Delta or 't Gen; $\mathrm{n}=2$ ) and a quadratic polynomial for age at calving. The spline function gave mean leptin concentrations for any DIM, while adjusting individual records for fixed effects as well as random effects for sire and animal to account for genetic and permanent environmental differences between the observations.

To get an overview of the relationships between traits, groups of cows differing \pm one SD of the mean were taken for each trait, including mean leptin concentrations per cow before (LEPpre) and after (LEPpost) parturition. For these groups the mean $\pm \mathrm{SE}$ was calculated for the other traits. Student's t-test was performed to indicate significant differences between the groups $(P<0.05)$.

Effect of traits on leptin curve. The effect of each trait (average over the first $80 \mathrm{~d}$ of lactation) on leptin concentrations during late pregnancy and lactation was modeled by fitting an interaction between a spline describing leptin concentrations as a function of DIM, and a spline describing leptin concentrations as a function of trait values. The complete model estimates a function that describes leptin curves at all different levels for the traits. Rather than presenting function parameters, the ASREML predicted function was used to predict leptin $( \pm$ SED) at different DIM for plus and minus one SD for each trait (i.e. DMI, MY, LW, EB, FPLA, FE, and milk components). To indicate significant differences, Student's t-test was performed for several DIM, and a value of $P<0.05$ was determined to be significant. To clarify relationships with leptin further, additional analyses were performed where the correlated traits DMI, MY, and LW were adjusted for each other and the residuals were included in the statistical model. Similar as before, leptin curves at different DIM were predicted for plus and minus one standard deviation of the residuals for each trait.

Reproduction traits. The same model was used to estimate a spline function and predict leptin concentrations at different DIM for FPLA and FE. In addition, a new model was used to investigate changes of leptin around the day of FPLA and FE. Therefore we expressed leptin concentrations for DIM relative to FPLA and, separately, leptin concentrations relative to $\mathrm{FE}$. 
Table 1. Averages and standard deviation for all traits analyzed $(n=304)$. The values of plus and minus one standard deviation were used to predict leptin concentrations at different DIM.

\begin{tabular}{lcccr}
\hline Item $^{1}$ & Mean & SD & Mean - SD & Mean + SD \\
\hline DMI (kg/d) & 18.3 & 1.6 & 17 & 20 \\
LW (kg) & 529.9 & 41.6 & 488 & 572 \\
MY (kg/d) & 31.2 & 4.3 & 27 & 36 \\
EB (MJ/d) & -2.58 & 11.38 & -14 & 9 \\
FPLA (d) & 30.2 & 17.5 & 13 & 48 \\
FE (d) & 70.7 & 40.9 & 30 & 112 \\
FY (g) & 1251 & 172.7 & 1075 & 1200 \\
PY (g) & 1066 & 121.7 & 950 & 1675 \\
LY (g) & 1479 & 207 & 1275 & 45 \\
F\% (g/kg) & 40.3 & 4.2 & 36 & 37 \\
P\% (g/kg) & 34.3 & 2.1 & 32 & 49 \\
L\% (g/kg) & 47.4 & 1.2 & 46 & \\
\hline
\end{tabular}

${ }^{1}$ Fat $(\mathrm{F})$, protein $(\mathrm{P})$, and lactose $(\mathrm{L})$ are presented both as total yields (FY, PY, LY) and in proportion to milk yield.

Leptin concentrations were determined by fitting a spline describing leptin concentrations as a function of FPLA or FE.

\section{RESULTS}

\section{Fixed Effects}

Table 1 presents averages and standard deviations for all measured traits. Mean performance \pm SE for groups of cows differing \pm one SD of the mean for each separate trait and for leptin concentrations pre- and postpartum are presented in Table 2. Cows with highest milk production had a higher intake, were lower in EB, and had a longer anestrous period (FPLA and FE) than lower producing cows. Heavier cows had higher prepartum leptin concentrations and cows in a more positive
EB had higher postpartum leptin concentrations. Also, cows in a more positive EB had 11.3 fewer days to FPLA. Furthermore, low leptin concentrations during pregnancy were associated with low leptin concentrations during lactation and vice versa.

Initially, month of calving was included in the model and leptin concentrations differed significantly between months (Figure 1). From February until May, leptin concentrations were lower than in the other months. Numbers of blood samples for leptin determination varied from as few as 79 in August to 334 in January. Because of these monthly differences, month of measurement should be taken as fixed effect in the further calculations. However, for a more precise adjustment, sample date instead of month of measurement was taken as fixed effect in the models. Genetic group and age at calving had no influence on leptin concentrations.

Table 2. Characteristics (mean \pm SE) of groups of cows differing \pm one SD for each separate trait and for leptin concentrations. LEPpre $=$ mean concentration of leptin during the prepartum period, LEPpost $=$ mean concentration of leptin during the postpartum period, $\mathrm{n}=$ number of cows in each group.

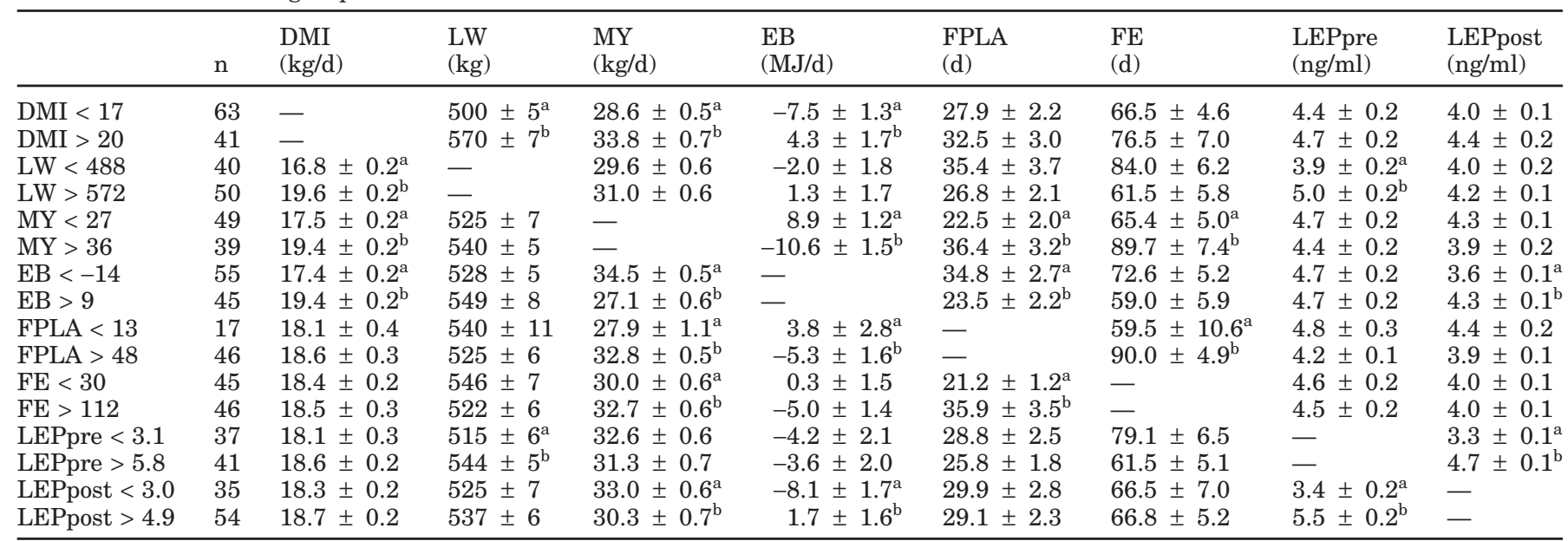

${ }^{\mathrm{a}, \mathrm{b}}$ When two rows are significantly different they are identified with different superscripts. 


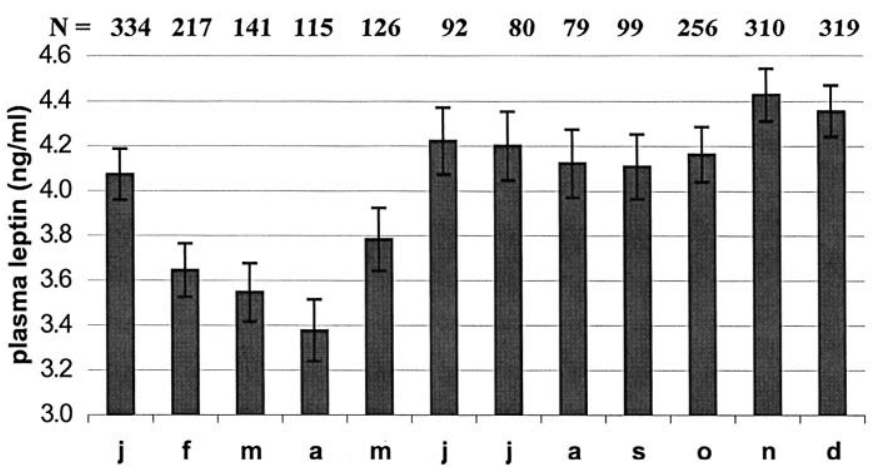

Figure 1. Plasma leptin concentrations $( \pm \mathrm{SE})$ per month of measurement after adjustment for DIM. $\mathrm{N}=$ number of samples in each month.

\section{Leptin Concentrations}

Leptin concentrations were high during late pregnancy and declined rapidly to a nadir at parturition (Figure 2). Shortly after parturition leptin concentrations seemed to rise, but they soon declined again to the nadir level at calving. This appeared to be constant until at least $70 \mathrm{~d}$ after parturition.

\section{Leptin Concentrations and Traits}

The two curves representing leptin concentrations at different DIM for plus and minus one SD for each trait are given in Figures 3 to 5 . Cows that consumed $17 \mathrm{~kg} / \mathrm{d}$ DM during the first $15 \mathrm{wk}$ of lactation had significantly lower $(P<0.05)$ concentrations of leptin during lactation than cows consuming $20 \mathrm{~kg} / \mathrm{d}$ DM (Figure $3 \mathrm{a}$ ); cows that consumed more food had higher leptin concentrations. Adjustments for potential effects of MY and LW (Table

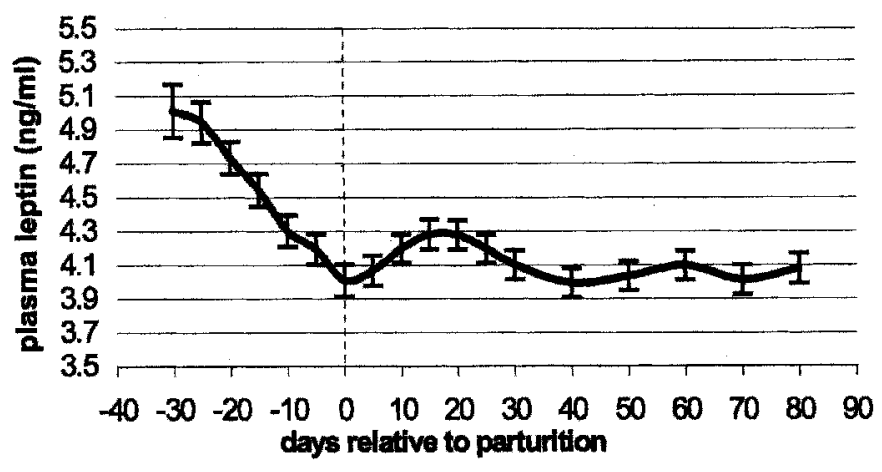

Figure 2. The lactation curve for leptin $( \pm \mathrm{SE})$. The day of parturition is indicated as a vertical dotted line. The concentration of leptin was measured by a RIA (Delavaud et al., 2000). The spline function used gives mean leptin concentrations and standard errors for any DIM, taking into account fixed and random effects included in the model.
2) only slightly affected the leptin curves for high and low DMI (Figure 3d).

Low weight cows $(488 \mathrm{~kg}$ ) showed significantly lower leptin concentrations than high weight cows $(572 \mathrm{~kg})$ (Figure $3 \mathrm{~b}$ ). Although LW was measured postpartum, the leptin difference was larger prepartum than during lactation. After adjusting for DMI and MY, there were only significant differences during pregnancy and very early lactation (Figure 3e).

High and low producing cows showed differences in leptin concentrations from $25 \mathrm{~d}$ of lactation onwards (Figure 3c). After adjusting for DMI and LW, significant differences were present after $\mathrm{d} 5$ of lactation (Figure 3f). From that day onwards high producing cows (36 $\mathrm{kg} / \mathrm{d}$ ) showed significantly lower plasma leptin concentrations than low producing cows $(27 \mathrm{~kg} / \mathrm{d})(P<0.05)$.

Cows with a mean EB of $-14 \mathrm{MJ} / \mathrm{d}$ during the first 15 wk of lactation did not differ in prepartum leptin concentrations from cows with a mean $\mathrm{EB}$ of $+9 \mathrm{MJ} / \mathrm{d}$ (Table 2, Figure 4). However during lactation, cows with an overall positive mean EB of $9 \mathrm{MJ} / \mathrm{d}$ showed significantly higher leptin concentrations than cows with a negative EB of $-14 \mathrm{MJ} / \mathrm{d}$. Furthermore, cows in a negative EB showed even lower leptin concentrations during lactation than the nadir level reached at parturition. Recovery of leptin to higher concentrations after the nadir at parturition was observed for cows in a positive EB. It seemed that these cows recovered sooner from the nadir level at parturition than cows in a negative EB.

For percentages of milk components, significant differences were found (results not shown). Cows with a higher leptin level during pregnancy had a higher percentage fat in milk during lactation. Cows with a higher leptin level during pregnancy and early lactation had a higher percentage lactose and cows with a higher leptin level during the whole period had a higher percentage protein in milk. For yields of milk components (fat, lactose, and protein yields in $\mathrm{kg}$ ), no significant differences were found, probably because percentages of milk components often are lower at higher milk yields.

\section{Leptin Concentrations and Reproductive Measures}

There were no differences in leptin concentration between cows with an early or a delayed FPLA but from d 15 of lactation onwards leptin concentrations were higher for cows that showed their FE earlier (d 30) than cows that had a delayed FE (d 112) (Figure 5). Changes of leptin before and after FPLA and FE were also investigated. Leptin concentrations rose linearly before and after FPLA and FE (Figure 6). For FPLA, standard errors were high, but for FE leptin concentrations on $\mathrm{d}-250,-50$, and 50 differed significantly. 


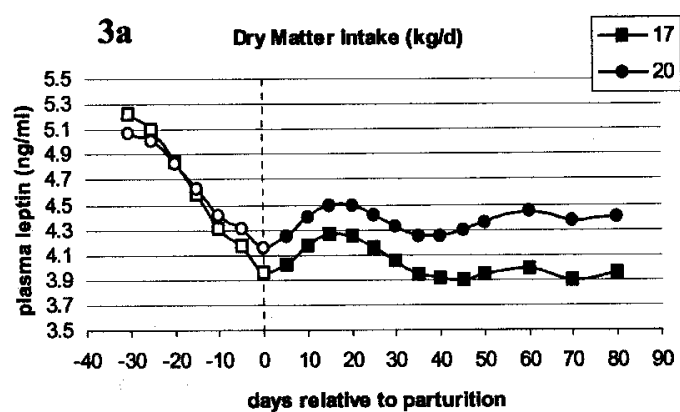

3d
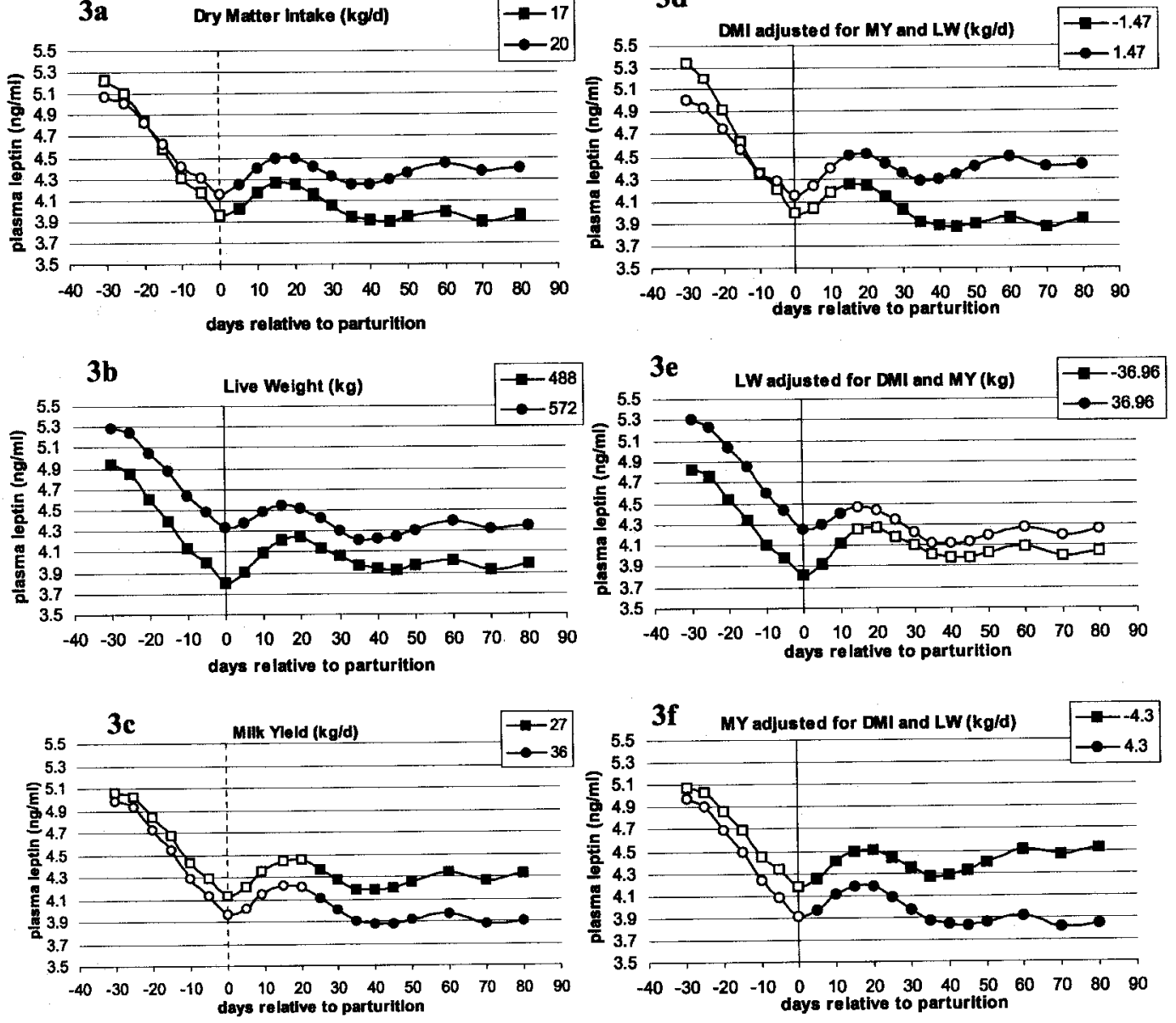

Figure 3. Leptin concentrations were modeled using two spline functions (and their interaction) for leptin, one function for DIM and one function for either DMI (a), LW (b), or MY (c). Leptin was predicted at different DIM for plus and minus one SD as two curves for each trait. In Figures d, e, and f DMI, LW and MY were adjusted for each other and the residuals were taken to predict leptin at different DIM. Filled squares and circles indicate significant differences $(P<0.05)$, open squares and circles indicate no significant differences $(P>0.05)$.

\section{DISCUSSION}

The aim of this study was to describe fluctuations in leptin concentrations during late pregnancy and lactation and to relate these fluctuations to dry matter intake, milk yield, live weight, energy balance, milk components, start of luteal activity, and first observed estrus.

\section{Fixed Effects}

We observed a decreased leptin concentration in the period from February until May (spring). In our experiment cows were housed inside with controlled lighting $(17 \mathrm{~h} / \mathrm{d}$ light) additional to daylight. These results are in contrast with Mann et al. (2000) who showed that leptin concentrations in monkeys reach a nadir in late summer (Aug. to Sept.) and a peak in late winter (Jan. to March). However, those monkeys were housed out-

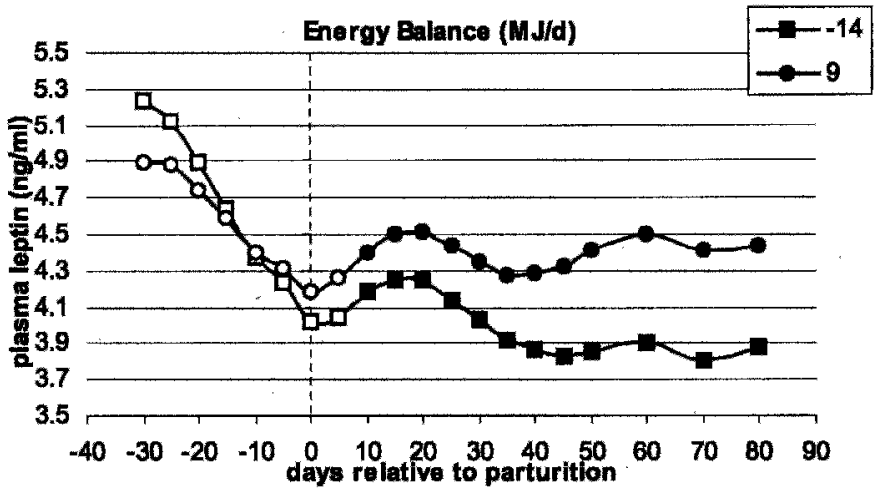

Figure 4. Relationship of energy balance with leptin concentrations. Leptin concentrations were modeled by fitting a spling for leptin on these traits with DIM included in the model. Leptin was predicted at different DIM for plus and minus one SD for mean EB during the first $80 \mathrm{~d}$ of lactation ( -14 and $9 \mathrm{MJ} / \mathrm{d})$. Filled squares and circles indicate significant differences $(P<0.05)$, open squares and circles indicate no significant differences $(P>0.05)$. 

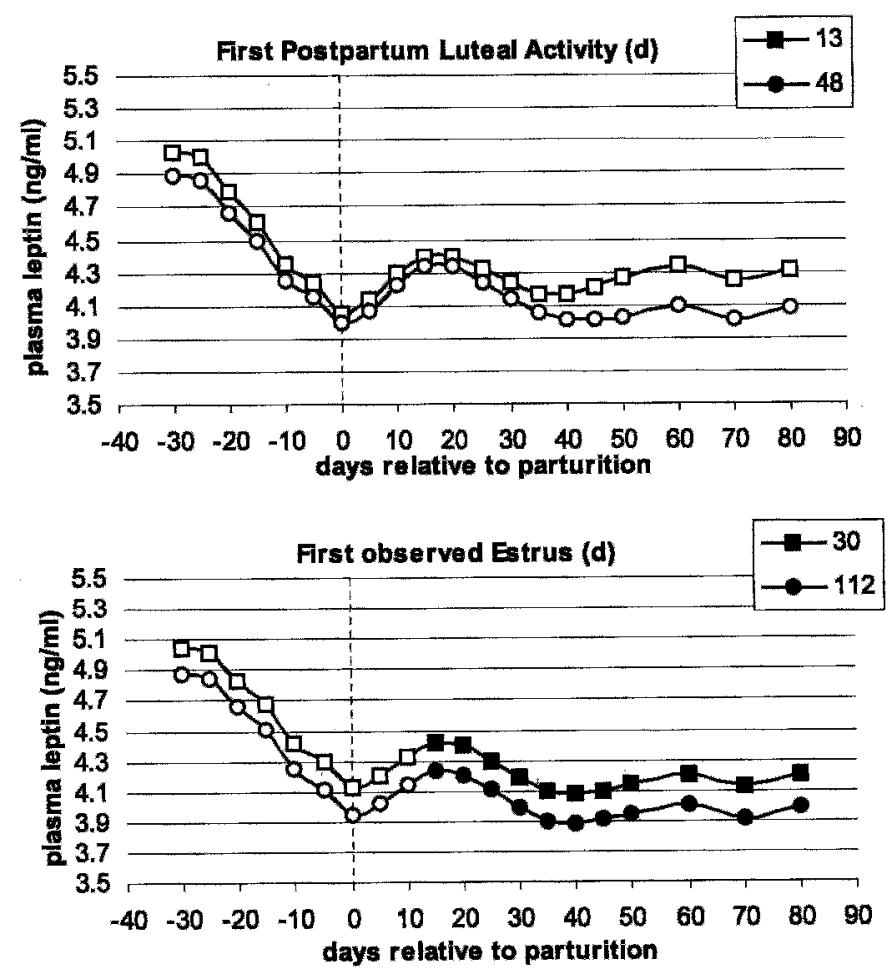

Figure 5. Relationship of reproductive traits with leptin concentrations. Leptin concentrations were modeled by fitting a spline for leptin on these traits with DIM included in the model. Leptin was predicted at different DIM for plus and minus one SD as two curves for FPLA and FE. Filled squares and circles indicate significant differences $(P<0.05)$, open squares and circles indicate no significant differences $(P>0.05)$.

doors with an attached temperature-controlled indoor area. Reist et al. (2001) reported that leptin concentrations are higher in cows calving in spring than in fall and Bocquier et al. (1998) reported that leptin concentrations are decreased when pair-fed sheep are exposed to a shorter photoperiod ( $8 \mathrm{~h} / \mathrm{d}$ vs. $16 \mathrm{~h} / \mathrm{d}$ light). These contrasts in results cannot be due to an unequal distribution of calving dates between the months, because in the analysis we adjusted for DIM. Also an unequal distribution of the number of samples between the months did not have an effect, because the number of samples was lowest in August $(\mathrm{n}=79)$ and highest in January $(\mathrm{n}=334)$. The differences between these studies could be due to differences between the studies in environment, feeding patterns or photoperiod. Genetic group and age at calving did not seem to influence leptin concentrations.

\section{Leptin Concentrations}

This study clearly shows that plasma leptin concentrations are high during late pregnancy and decline to
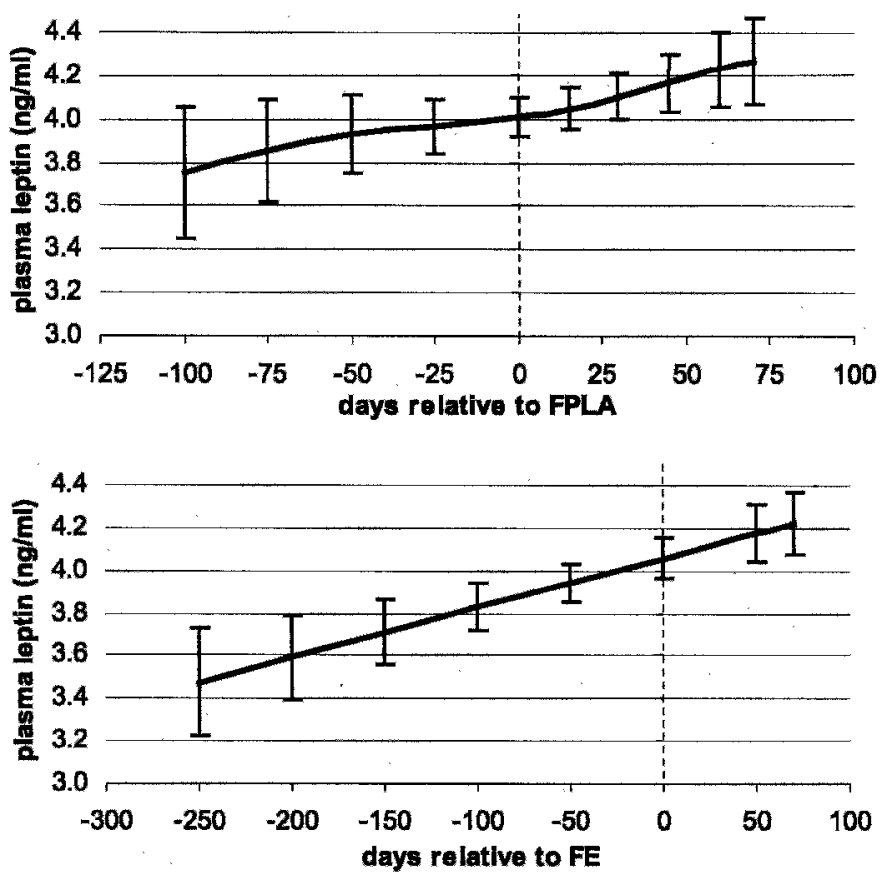

Figure 6. Leptin concentrations before and after start of luteal activity and first observed estrus. The lactation curve of leptin was included in the model to adjust for the effect of DIM on leptin concentrations. Leptin concentrations are measured from day -30 until day 80. FPLA was measured from day 0 until day 100 . FE was measured from day 0 until day 250 . When a cow has a $\mathrm{FE}$ at day 200 , it is possible to have leptin concentrations at $230 \mathrm{~d}$ before FE.

a nadir at parturition. This is in agreement with earlier reports in cows and sheep (Kadokawa et al., 2000; Block et al., 2001; Ehrhardt et al., 2001; Holtenius et al., 2001;

Kokkonen et al., 2002; McFadin et al., 2002).

Leptin concentrations may be high during pregnancy as a result of the high energy intake necessary for the lactation period. This could be due to a specific decrease of the long-active form of the leptin receptor at hypothalamic level (Garcia et al., 2000), which means that there are fewer signals to reduce food intake. On the other hand, an increase in the concentrations of the soluble binding protein of the leptin receptor during pregnancy (Gavrilova et al., 1997) could also be responsible for the increased food intake. Assuming that the leptin-binding protein inhibits leptin signaling, the high concentrations observed would cause leptin resistance.

It has been speculated that the placenta produces leptin and that the decline around parturition is caused by the expulsion of the placenta (Hoggard et al., 2001), but in our study the decline already started by $30 \mathrm{~d}$ before parturition. Block et al. (2001) and Reitman et al. (2001) reported that in mice, ovine, and bovine species, leptin might not be synthesized by placental tissue. In nonruminant species, the decline in leptin concentra- 
tion near parturition may be important for inducing the hyperphagia that is necessary for milk production (Brogan et al., 1999). However, the expected increase in leptin concentrations in response to this hyperphagia is abolished or actively suppressed during lactation (Pickavance et al., 1998).

\section{Leptin Concentrations and Traits}

Our results show that feed intake influences the production of leptin during the lactation period; a higher DMI is associated with higher leptin concentrations. These results are in agreement with data in nonpregnant, nonlactating sheep and cattle that received a higher feeding level of energy and showed higher leptin concentrations (Delavaud et al., 2000; Chilliard et al., 2001; Delavaud et al., 2002). Buyse et al. (2001) reported that a higher DMI increases insulin concentrations and this positively influences the production of leptin in adipose tissue.

Figure $3 \mathrm{~b}$ shows that LW affects leptin concentrations during pregnancy and lactation, but adjusting for effects of feed intake and milk yield reduced the effect of LW on leptin concentrations during lactation (Figure 3e). Table 2 shows that this reduced effect during lactation mostly can be ascribed to differences in DMI, because cows with $\mathrm{LW}>572 \mathrm{~kg}(\mathrm{n}=50)$ have a higher DMI than cows with $\mathrm{LW}<488 \mathrm{~kg}(\mathrm{n}=40)$ whereas MY did not differ significantly between the high- and lowweight cows.

Milk yield influences leptin concentrations during lactation as higher MY was related to lower leptin production, particularly after adjustment for LW and DMI. Again, Table 2 shows significant differences in DMI between high- and low-producing cows; thus DMI is the more important adjustment factor. Mann and Blache (2002) did not find a relationship between MY and leptin concentrations but they used the RIA developed by Blache et al. (2000) which gave lower values (0.4 to $1.2 \mathrm{ng} / \mathrm{ml}$ ) than the RIA (2 to $14 \mathrm{ng} / \mathrm{ml}$ ) developed by Delavaud et al. (2000) and Ehrhardt et al. (2000).

A mean positive or negative energy balance during lactation influences circulating leptin concentrations. During lactation, cows in a positive EB have significantly higher leptin concentrations than cows in a negative EB (Figure 4 and Table 2). Table 2 shows that cows with a mean positive $\mathrm{EB}(9 \mathrm{MJ} / \mathrm{d})$ or more have a higher feed intake, a higher weight (NS) and a lower milk yield than cows with a mean negative EB $(-14 \mathrm{MJ} / \mathrm{d})$. If we look to Figure 3, we see that these groups of cows all have higher leptin concentrations. Because energy balance is calculated from components like DMI, MY and LW, the relationship of leptin with DMI, MY and LW can be ascribed to the relationship of leptin with EB.
This is confirmed by studies of Block et al. (2001) and Reist et al. (2001) who also postulated a link between EB and leptin. The suggestion of Reist et al. (2001) that leptin variance could be linked more to individual cows than to either BCS, EB or LW may suggest that there is a genetic component affecting leptin concentrations. This would not be surprising as genetic components play a major role in physiological pathways. To estimate the genetic and individual cow component during the lactation period, a more sophisticated sire and animal component needs to be included in the model.

Apart from the differences in leptin concentrations we also observed differences in the recovery of leptin concentrations from the nadir level at parturition. This recovery seemed to depend on the extent of negative EB. In this study we see that cows in a positive EB, which have less fat mobilization, show a recovery of leptin concentrations after parturition and that cows in a negative EB even reach leptin concentrations below the nadir level at parturition. The recovery of leptin concentrations after parturition seems to depend on the quantity of fat deposition.

\section{Leptin Concentrations and Reproduction}

In our study, no relationship between leptin and FPLA was found, but significant differences in postpartum leptin concentrations were observed for FE. The first observation is in agreement with Holtenius et al. (2002), who reported that postpartum leptin concentrations were not related to time to return to cyclicity. An explanation for the absence of a relationship between FPLA and leptin concentrations might be that leptin concentrations are not low enough to negatively affect ovulatory cycles.

The lack of a relationship between FPLA and leptin concentrations in combination with a negative relationship between FE and leptin, might indicate a relationship between and problems with estrous expression (e.g. silent estrus and subestrus). In the present study we found a difference of almost $40 \mathrm{~d}$ (30.2 and $70.7 \mathrm{~d}$, respectively) between mean FPLA and FE values (Table 1) and a correlation between FPLA and FE of $0.26(P$ $<0.01)$. Assuming reliable estrous detection, these results might indicate that animals with higher leptin concentrations have a better estrous expression. Schopper et al. (1993) suggested a relationship between high milk yield (i.e. low leptin concentration in this study) and poor estrous expression.

It seems that a minimum level of leptin is required to induce the first postpartum LH surge as previously suggested by Huszenicza et al. (1999). In our study leptin concentrations rose linearly before and after FPLA and FE and it seemed that a permissive level of 
$4 \mathrm{ng} / \mathrm{ml}$ had to be reached to induce both FPLA and FE. Bocquier et al. (1998) also suggested this in case of a sheep model.

We observed no clear nadir in leptin concentrations before FPLA or FE. This is in contrast with the results of Kadokawa et al. (2000) who showed a relationship between days to leptin nadir and days to first ovulation.

In summary, leptin concentrations during lactation reflect changes in EB and those fluctuations were not directly related to onset of luteal function. However, it seems that leptin concentrations may be related to expression of estrus. The recovery of leptin concentrations after the nadir at parturition seemed to be associated with the level of negative energy balance and thus the amount of fat that is re-accumulated during lactation.

\section{ACKNOWLEDGMENTS}

We thank Henry van der Gaast for collecting all data. We also thank Leo Kruijt for refining the leptin RIA and Michel Breuer and Joop Testerink for their excellent laboratory work in performing the RIA. This work was financially supported by CR-Delta, Arnhem, the Dutch Ministry of Economical Affairs BTS 98194 and the Dutch Ministry of Agriculture, Nature Management and Fisheries.

\section{REFERENCES}

Ahima, R. S., J. Dushay, S. N. Flier, D. Prabakaran, and J. S. Flier. 1997. Leptin accelerates the onset of puberty in normal female mice. J. Clin. Invest. 99:391-395.

Blache, D., R. L. Tellam, L. M. Chagas, M. A. Blackberry, P. E. Vercoe, and G. B. Martin. 2000. Level of nutrition affects leptin concentrations in plasma and cerebrospinal fluid in sheep. J. Endocrinol. 165:625-637.

Block, S. S., W. R. Butler, R. A. Ehrhardt, A. W. Bell, M. E. Van Amburgh, and Y. R. Boisclair. 2001. Decreased concentration of plasma leptin in periparturient dairy cows is caused by negative energy balance. J. Endocrinol. 171:339-348.

Bocquier, F., M. Bonnet, Y. Faulconnier, M. Guerre-Millo, P. Martin, and Y. Chilliard. 1998. Effects of photoperiod and feeding level on perirenal adipose tissue metabolic activity and leptin synthesis in the ovariectomized ewe. Reprod. Nutr. Dev. 38:489-498.

Brogan, R. S., S. E. Mitchell, P. Trayhurn, and M. S. Smith. 1999. Suppression of leptin during lactation: contribution of the suckling stimulus versus milk production. Endocrinol. 140:2621-2627.

Buyse, M., S. Viengchareun, A. Bado, and M. Lombes. 2001. Insulin and glucocorticoids differentially regulate leptin transcription and secretion in brown adipocytes. Faseb. J. 15:1357-1366.

Canfield, R. W., and W. R. Butler. 1990. Energy balance and pulsatile LH secretion in early postpartum dairy cattle. Domest. Anim. Endocrinol. 7:323-330.

Chehab, F. F., M. E. Lim, and R. Lu. 1996. Correction of the sterility defect in homozygous obese female mice by treatment with the human recombinant leptin. Nat. Genet. 12:318-320.

Chilliard, Y., M. Bonnet, C. Delavaud, Y. Faulconnier, C. Leroux, J. Djiane, and F. Bocquier. 2001. Leptin in ruminants. Gene expression in adipose tissue and mammary gland, and regulation of plasma concentration. Domest. Anim. Endocrinol. 21:271-295.

Delavaud, C., F. Bocquier, Y. Chilliard, D. H. Keisler, A. Gertler, and G. Kann. 2000. Plasma leptin determination in ruminants: effect of nutritional status and body fatness on plasma leptin concentration assessed by a specific RIA in sheep. J. Endocrinol. 165:519-526.

Delavaud, C., A. Ferlay, Y. Falconnier, F. Bocquier, G. Kann, and Y. Chilliard. 2002. Plasma leptin concentration in adult cattle: Effect of breed, adiposity, feeding level, and meal intake. J. Anim. Sci. 80:1317-1328.

Ehrhardt, R. A., R. M. Slepetis, J. Siegal-Willott, M. E. Van Amburgh, A. W. Bell, and Y. R. Boisclair. 2000. Development of a specific radioimmunoassay to measure physiological changes of circulating leptin in cattle and sheep. J. Endocrinol. 166:519-528.

Ehrhardt, R. A., R. M. Slepetis, A. W. Bell, and Y. R. Boisclair. 2001. Maternal leptin is elevated during pregnancy in sheep. Domest. Anim. Endocrinol. 21:85-96.

Garcia, M. D., F. F. Casanueva, C. Diequez, and R. M. Senaris. 2000. Gestational profile of leptin messenger ribonucleic acid (mRNA) content in the placenta and adipose tissue in the rat, and regulation of the mRNA levels of the leptin receptor subtypes in the hypothalamus during pregnancy and lactation. Biol. Reprod. 62:698-703.

Gavrilova, O., V. Barr, B. Marcus-Samuels, and M. Reitman. 1997. Hyperleptinemia of pregnancy associated with the appearance of a circulating form of the leptin receptor. J. Biol. Chem. 272:30546-30551.

Gilmour, A. R., B. R. Cullis, S. J. Welham, and R. Thompson. 2001. ASREML, Reference Manual.

Halaas, J. L., K. S. Gajiwala, M. Maffei, S. L. Cohen, B. T. Chait, D. Rabinowitz, R. L. Lallone, S. K. Burley, and J. M. Friedman. 1995. Weight-reducing effects of the plasma protein encoded by the obese gene. Science 269:543-546.

Hoggard, N., P. Haggarty, L. Thomas, and R. G. Lea. 2001. Leptin expression in placental and fetal tissues: does leptin have a functional role? Biochem. Soc. Trans. 29:57-63.

Holtenius, K., S. Agenas, C. Delavaud, and Y. Chilliard. 2001. Effect of dry period feed intake on plasma leptin in dairy cows. Biotechnology. Agronomy and Environment 5 p58 (special issue).

Holtenius, K., S. Agenas, H. Gustafsson, C. Delavaud, and Y. Chilliard. 2002. The effect of feeding intensity during the dry period on plasma leptin and time to return to cyclicity in dairy cows. Proc. Brit. Soc. Anim. Sci. p1 (abstract).

Huszenicza, G., M. Kulcsar, J. A. Nikolic, J. Schmidt, P. Korodi, L. Katai, S. Dieleman, P. Ribiczei-Szabo, and P. Rudas. 1999. Plasma leptin concentration and its interrelation with some blood metabolites, metabolic hormones and the resumption of cyclic ovarian function in postpartum dairy cows supplemented with monensin or inert fat in feed. Occ. Publ. Br. Soc. Anim. Sci. 2:405-409.

Jolly, P. D., S. McDougall, L. A. Fitzpatrick, K. L. Macmillan, and K. W. Entwistle. 1995. Physiological effects of undernutrition on postpartum anoestrus in cows. J. Reprod. Fertil. Suppl. 49:477-492.

Kadokawa, H., D. Blache, Y. Yamada, and G. B. Martin. 2000. Relationships between changes in plasma concentrations of leptin before and after parturition and the timing of first post-partum ovulation in high-producing Holstein dairy cows. Reprod. Fertil. Dev. 12:405-411.

Kokkonen, T., J. Taponen, S. Alasuutari, M. Nousiainen, T. Anttila, L. Syrjala-Qvist, C. Delavaud, Y. Chilliard, M. Tuori, and A. T. Tesfa. 2002. Plasma leptin in transition dairy cows. Effects of body fatness, ambient temperature and dietary factors. Proc. Brit. Soc. Anim. Sci. p 92 (abstract).

Mann, D. R., M. A. Akinbami, K. G. Gould, and V. D. Castracane. 2000. A longitudinal study of leptin during development in the male rhesus monkey: the effect of body composition and season on circulating leptin levels. Biol. Reprod. 62:285-291.

Mann, G. E., and D. Blanche. 2002. Relationship between plasma leptin concentration and reproductive function in dairy cows. Proc. Brit. Soc. Anim. Sci. p 2 (abstract).

McFadin, E. L., C. D. Morrison, P. R. Buff, N. C. Whitley, and D. H. Keisler. 2002. Leptin concentrations in periparturient ewes and their subsequent offspring. J. Anim. Sci. 80:738-743.

Morrison, C. D., J. A. Daniel, B. J. Holmberg, J. Djiane, N. Raver, A. Gertler, and D. H. Keisler. 2001. Central infusion of leptin into 
well-fed and undernourished ewe lambs: effects on feed intake and serum concentrations of growth hormone and luteinizing hormone. J. Endocrinol. 168:317-324.

Mwaanga, E. S., and T. Janowski. 2000. Anoestrus in dairy cows: causes prevalence and clinical forms. Repr. Dom. Anim. 35:193-200.

Nagatani, S., Y. Zeng, D. H. Keisler, D. L. Foster, and C. A. Jaffe. 2000. Leptin regulates pulsatile luteinizing hormone and growth hormone secretion in the sheep. Endocrinol. 141:3965-3975.

Pickavance, L., M. Tadayyon, G. Williams, and R. G. Vernon. 1998. Lactation suppresses diurnal rhythm of serum leptin. Biochem. Biophys. Res. Commun. 248:196-199.

Reist, M., D. Erdin, D. von Euw, K. Tschumperlin, C. Delavaud, Y. Chilliard, H. Hammon, N. Kunzi, J. W. Blum. 2001. Concentrate feeding strategy in lactating dairy cows: metabolic and endocrine changes with emphasis on leptin. 11th Int. Conf. Prod. Diseases Farm Anim.

Reitman, M. L., S. Bi, B. Marcus-Samuels, and O. Gavrilova. 2001. Leptin and its role in pregnancy and fetal development, an overview. Biochem. Soc. Trans. 29:68-72.

Schopper, D., R. Schemer, U. Weiler, and R. Claus. 1993. Influence of milk yield on the fertility of dairy cows postpartum: evaluation of progesterone profiles. Repr. Dom. Anim. 28:225-235.

Veerkamp, R. F., J. K. Oldenbroek, H. J. Van der Gaast, and J. H. Van der Werf. 2000. Genetic correlation between days until start of luteal activity and milk yield, energy balance, and live weights. J. Dairy Sci. 83:577-583. 